\title{
An Exploratory Study for the Role of System Mind in Creative Design Thinking
}

\author{
Janan Mustafa \\ Scientific College of Design, Oman
}

\begin{abstract}
One of the key strategic aspects of creative design thinking described by Nigel Cross is taking a broad systems approach or what is called "system mind". This paper aims to clarify the "system mind" in the design process, through which novel architectural design concepts can be achieved. The general problem is to reveal the places where the system mind is used in the design process. The characteristics and context of this strategy are reconstructed from previous literature. Based on the analytical approach a case study has been conducted, and the indicators of system mind have been identified within the general frame of creative thinking. The results show that system mind is used twice effectively while shaping the body of a holistic design concept
\end{abstract}

\section{Introduction}

In his book "Design Thinking", Cross studied the way of thinking of three innovative designers and came up with three approaches of creative thinking, which appear to be common to all the innovators he studied: (1) taking a broad systems approach to the problem (System Mind), (2) framing the problem in a personal perspective, and (3) designing from first principles.

Cross has clarified the systems approach by adopting Maccoby's definition of "a system mind":

"The innovator has a system mind, one that sees things in terms of how they relate to each other in producing a result, a new gestalt that to some degree changes the world." [1].

This definition clarifies that the systems approach is used while solving design problems; it is concerned with producing the solution rather than the structuring of the problem. Maccoby differentiates between an innovator's holistic approach of solving the problem and an engineering partial approach of developing solutions:".' For example, one can think about a car in terms of all its parts working together to make it go....In contrast, most engineers do not think in systems terms. They are concerned about designing a good piece-part, like a clutch.'." [1].

John Pourdehnad emphasized that designers should learn how parts interact rather than looking at their performance independently [7]. Cross further explained his point of view of the broad systems approach and projected Maccoby's definition of a system mind on his own case studies of innovative designers. He concluded that these designers have a holistic view of the problem; goals such as winning the race is a larger picture of developing a pit stop for a racing car by the innovator Gordon Murray, or easy use and maintenance is a general view that facilitates the development of Frister and Rossman's new sewing machine by innovative designer Kenneth Grange. Grange perceived the problem of designing a new sewing machine from the user's point of view rather than accepting the brief as given from the client. The brief was concerned with introducing a new look to a sewing machine: Grange however shed light on another part of the problem, that is the easy and pleasant use and maintenance of the machine, and he developed a machine that facilitated ease of use and in turn achieved a new style or form of machine.

\section{Parallel Lines of thought and the system mind}

Bryan Lawson has interviewed many internationally respected architects and noticed that good architects keep "parallel lines of thoughts" while carrying through the design process. While citing Lawson's study, Cross mentioned that these thoughts are relevant to the same job at the same time and that designers use them to cope with uncertainty. Cross clarified the parallel lines of thought by bringing one example of Lawson's case studies, that is Robert Venturi's Sainsbury Wing extension to the National Gallery in London. The American architect kept two lines of thought throughout the process: one was how to deal with the circulation of the extension in relation to that of older exhibition spaces, and the second line of thought was how to relate the form of the new extension to the old/historic context of the site. Further, Lawson in his paper " Parallel lines of thought" described the parallel lines of thought as 'modes' with different ' features' in which the designer keeps thinking separately and might have many features for each but at the end there must be one solution. Cross pointed out that Lawson considered the moment of gathering the lines into one solution as one of the most critical times for the designer: 
"...If this is attempted too early, ideas which are still poorly understood may get lost, while if this is left too late they may become fossilised and too rigid. There is no formula or easy answer to this conundrum, the resolution of which probably depends almost entirely on the skill of and sensitivity of the designer...." [1].

These parallel lines of thought are solution directed/focused rather than problem directed or focused, or they are concerned with the form of the solution rather than the structure of the problem. Lawson talked also about another three 'concepts' (in addition to the concept of modes) that can summarize the way in which designers think creatively to solve problems. The four concepts are: governing principles, primary generators, modes and features, and parallel lines of thought [6].Knowing the first two concepts is crucial to understanding the two second concepts, thus his point of view on the holistic approach, or the system mind ( parallel lines of thought) can be understood. He described governing principles as a thread that connects the design work. They are general principles such as applying the ecological principles of high rise buildings in a tropical climate (Cross referred to them as naming the problem by determining the factor or factors that would be in focus).

Lawson also referred to Jane Darke's study for innovative designers and design process [2] to explain his second concept of the primary generator. He pointed out that Darkehas found that designers create solutions before they have even understood the problem; they actually understand the problem by solving 'hypothetical' solutions; she called them the primary generators [6], ( Cross calls them tentative solutions). They could be related to the governing principles or simply be factors related to the site, function, form or environment: "...These 'primary generators' acted as hypotheses enabling the architects to explore the inadequacies of their yet illformed solution and through this to learn more about the problem"[6]. Lawson explained that the importance of these solutions, or primary generators, lies in the fact that they are a device to enable the designer to feel the problem and understand it. What makes this device so successful is this ability to freeze some aspects of the problem until the mind can pay further attention to it.

While working within the space of the primary generator, designers follow different ways and methodologies to suggest alternative sets of ideas/solutions. There is a variety of ways to look at design solutions using what Lawson calls 'structural forms' that organise the designer's knowledge, namely: functional, environmental, structural, and formal. He also calls them 'modes' and they have certain features: envelope mode; component mode, system mode. These modes not only help in representation and structuring the designer's knowledge of the building but they can also determine how the building might look. Therefore Lawson said that they are solution directed rather than problem directed. They follow and depend on the designer's attitudes of defining what the building is: for example, a designer like Mies Van der Rohe defines the building in terms of its wall components. Designers can create the ordering logic using these "modes" as a kind of argument, a designer may look at the building as an envelope, as components or as systems of integrated services. He further clarified his idea by giving two examples: Mies van der Rohe's Germany pavilion in Barcelona, in which he used a logic of components for the walls, in comparison with Stirling and Wilford who used the logic of the $3 \mathrm{D}$ envelope in their project forCornell University Centre for the Performing Arts. Designers can create many of these modes before reaching one possible solution; they can stay in parallel for a time:"...It seems quite common for these separate lines of thought to remain parallel for some time during the design process. The good designer seems to be one who is not unduly concerned too early in the process about any lack of resolution. There is thus no rush to get thoughts to converge. Such a designer is capable of generating new and alternative lines of thought without allowing this to throw the process off the rails, as it were." [6].

Lawson also referred to Rowe's study of designers at work, in which he reported that designers solve the parallel lines of thought by the use of integrating notions or "meta- ideas." Rowe showed how designers adhere to a "big-idea" when persistent competition occurred between two themes [8]. In such cases, designers put great effort to make the initial idea work to avoid returning to the starting point to pick up a completely new idea. They manage this point by making the structure of the subproblems pliable and flexible so that they can be solved under the umbrella of the big-idea.

Here, some detailed study is needed to explain the formation of the lines of thoughts and answer the question of content. This paper is going to make use of a specialised study in architectural programming.

\section{Architectural programming and system mind}

Donna Duerk developed an issue-based programming tool to manage the early stages of the design process. This tool manages the relevant information and develops a strategy of a coherent structure for the information hierarchy. The structure starts by categorising the project facts into groups in order to define the issues of interest, which are then filtered through consideration of both the client's and the designer's values. The structure proceeds towards developing design goals and the related 
performance requirements, until partial design concepts/ solutions are reached [3], see Figure 1. She asserts the importance of developing an overall concept that governs the design process, she calls it an organisational concept (super organising idea, mega concept, theme, or parti). It can be used at every scale and stage of design because it has the capacity to overlap with issue concerns [3]. By reviewing the tree diagram of Figure 1, one can trace the lines of thought passing through various activities to develop a hierarchy of partial concepts. Such a hierarchy captures one aspect of system mind, that is the interconnections between activities that develop the partial design concepts. Is it possible for one partial concept to dominate the design and let all lines of thought go under it? How could this happen?

In his explanation of the explicit approach of the design process, Barry D. Yatt summarises it into three steps [10]. Firstly, the designer has to develop premises in order to identify the problem and address the aspects of the project in a preliminary statement. Secondly, a program concept has to be developed, that is to interpret the program by examining it from the client's point of view and bounding it to the designer's own ideas of the project. This can be done by searching for orders, emphasis and relevance in the program. Finally, a design concept should be developed by defining the aesthetic mood or design philosophy. This final step identifies the project's attitude of expression. Moreover, Yatt shows the importance of looking for a parti idea or a metaphor, which can clearly address the issues of the project. Designers have to find the overriding image that guides the attitude toward massing. Here, the Design concept becomes the graphic seed of the project in which a physical image has to dominate and guide it towards more detailed developments.

Yatt's study implies very important notes regarding the development of the program concept. It seems that the key to bridging between the program concept and the design concept is to develop the area of performance requirement. The emergent patterns could be modified to be more consistent and compatible with each other. Consistency and compatibility among the emergent patterns are considered as the key aspect of a successful leap towards developing a design concept: "...'Look at all the conclusions you've generated from your Premise Development. Are they all compatible with each other? Do any of your conclusions need to be modified in order to be consistent with any of your other conclusions? Do you see any patterns emerging? Anything that begins to suggest itself as a point of departure for your design concept?'....", [10].

After describing the process of developing a design concept, we need to know how and where the system mind can take place and make it possible to think in partial solutions/concepts in terms of how they relate to each other and to the whole. Does the system mind have any role in the formation of the organising concept? How could partial design ideas be turned into a holistic design solution and what is the role of system mind in developing a consistent pattern of thought?

To answer all of these questions we have to explore the design process and indicate the places where the system mind takes place. The exploration of the process can be achieved by conducting an analytical study of a creative design project. The tree diagram of Duerk can be used for analytical purposes because it is an issue-based model. Although it can answer the question of the content (what to do and what to deal with; issues; goals; design concepts), it does not have the capacity to tell us how to design nor does it have the capacity to show the critical decisions that lead to creative solutions. Apparently, an operational definition for the system mind should be developed, then to be applied in a practical case study and finally to be presented using Duerk's diagram.

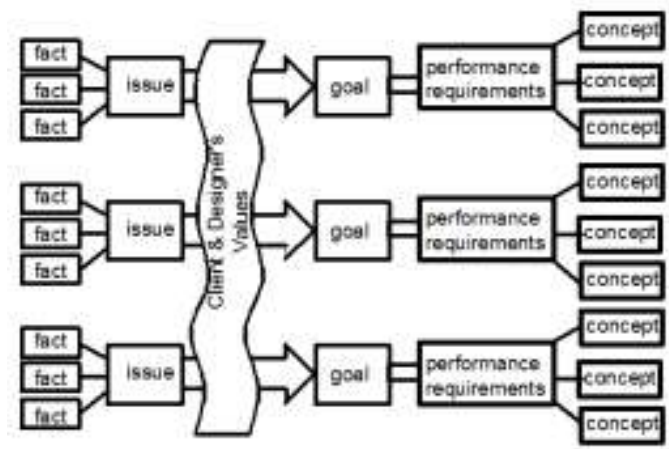

Figure 1. Duerk's Issue- Based Architectural Programming Model

\section{System mind: operational definition}

Jon Kolko is concerned with the synthesis in the design process. In his study [5], he explains how patterns of thoughts are formed from a chaos of data and information. Designers attempt to find relationships or themes in the available data to reveal a hidden meaning that is applicable to the design task. Kolko sees that the process of synthesising a meaningful whole is due to sense making, which is an internal process. Sense making is necessary not only for finding connections between elements but also for forcing an external view on things [5].

In this way, sense making is a cognitive operation that can put designers' expectations on a path or into a track by forming connections between what is available. A strong mental model has to be built out of vast data by finding connections between seemingly unconnected information. Searching for patterns of connections among mountains of information demands two things: being selective in 
choosing the information and being able to see information in one design space, [5]. Having found a pattern or patterns of thought, designers seek for an external idea that gathers all the patterns into one whole. In order to find this idea or concept, designers have to experience "abductive reasoning" with which a hypothesis/idea not related to the body of the premises / data or external to the data in hand is concluded. This possible solution-idea is a kind of concept under which all information (data, goals, issues arising from the analytical stage) are adjusted and controlled.

Researchers always refer to abductive reasoning as a special kind of reasoning experienced only by designers to suggest a design solution. Kolko clarifies the main difference between abductive reasoning and both inductive and deductive reasoning. Abductive reasoning comes up with a conclusion in the form of a hypothesis that is external and not related to the premises, [5]:

I've done something like A before, but the circumstances weren't exactly the same.

I've seen something like $B$ before, but the circumstances weren't exactly the same.

I'm able to abduct that $C$ is the reason $B$ is occurring.

Kolko refers to two theories attempting to explain how "abductive reasoning" comes to designers. There is Peirce's theory of fallible insight experienced "like a flash". Kolko explains the circumstances which make it possible for this flash to take place; it is this gathering of things which (he) "had never before dreamed of putting together." The other theory is that of Johnson Laird; he came up with an opposing argument. He claims that in the context of creative problem solving the insight is developed, but does not come as a flash, rather in a process of four steps [5]:

- the constraints of the existing strategy failed to solve the problem;

- new constraints suggests an implied consideration;

- enlarging the problem space to allow for further considerations to take place;

- further changes to the constraints can lead to solving the problem.

In any of these approaches designers experience three cognitive operations necessary to produce a design solution; these are: prioritising (not all the available data are of the same value, designers subjectively put data into a prioritised order in a way that seems reasonable), judging (determine what is most significant in the current problem-solving context as not all of the data are relevant), and the forging of connections (find relationships between the discrete elements of data). Kolko further explains the role of forging the connections in inducing a hypothesis based on inference and producing new knowledge. When they combine new elements extracted from a previous designer's experience with existing elements, designers seemingly are using the abductive way of thinking.

Apparently a broad systems approach implies two cognitive operations:

- enlarging the scope of the problem to go beyond what is given;

- forging connections where one sees things in terms of how they relate to each other.

As has been mentioned earlier in this paper, Donna Duerk, in her study of managing the design process, has introduced an issue- based programming model- the tree diagram- which can show the development of partial concepts at an early stage of the project. This paper is going to use the structure of this model as a tool to present the analysed data from the project. The aim is to find the places where system mind is used in this model and discover the hidden steps in the structure that lead to creative solutions.

Enlarging the scope of thinking and forging connections are going to be used as mechanisms to show the places where system mind is used. The increase in the number of parallel lines of thoughts and /or the development of new lines within the same line of thought are going to be used as indicators for the first operation (enlarging the scope). As for the second operation (forging connections), the combined lines of thoughts are going to be used as indicators.

The occurrence of abductive reasoning is going to be used as an indication of the efficiency of using system mind. It can be explored by comparing between those partial ideas and concepts of each line of thought on the one hand and the resultant holistic design concept on the other. If this latter is different from them or not related to any of the ideas that have generated it, which means the insight has taken place and the system mind is used effectively.

\section{Explore the System Mind in the Design Process}

In order to achieve the goal of revealing the places where system mind can be used while designing, we need to find a case study in which the designer describes the way of developing the design. This paper is going to analyse the UK Pavilion project in Expo Shanghai 2010 by Thomas Heatherwick. He describes his design in Ted Talk, the video and the transcript of his talk are available on line (https://www.ted.com/talks/thomas_heather wick); this description is documentation of the way he thought about his project. The transcript of his talk and also some other references of critics are going to be used in order to build a whole picture of the way he tackled the design problem. 
This architect is famous for searching for beauty by use, and this project is almost a symbolic one: however, Heatherwick intended to design an iconic form that is pleasant in both appearance and to use, Figure 2 shows a picture of the pavilion (Source: .https://www.detail-online.com/article/designing-theseed-cathedral-14225/).

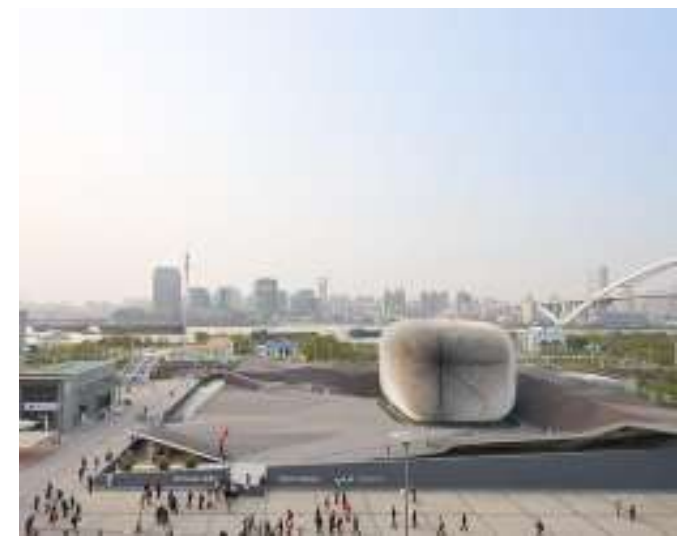

Figure 2. UK Pavilion, Shanghai Expo 2010, Architect Thomas Heatherwick

Figures 6 and 7 show the parallel lines of thought. They start from the premises of the brief which include issues highlighted by the client and from site analysis as two main factors on which to focus. The designer declared goals related to these issues, Figure 3. For symbolic issues, the brief of the client (the UK Government) is to design a pavilion that would be iconic and represent the UK's cultural and commercial ambitions; simply put, it should represent the UK. The architect declared that his goal is not to represent the UK's heritage directly:

Rather than showing a range of UK expertise or falling into the trap of showing parts of UK heritage, The architect decided to highlight the role of Britain in integrating nature into the city. The source of this idea is the theme of the Expo 2010 'better city, better life. ',[4].

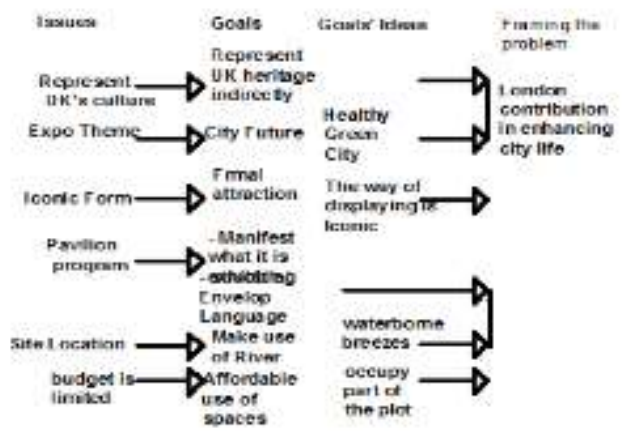

Figure 3. The structure of framing the problem
The architect interpreted the theme in terms of how the future of cities could be identified. He declared that his goal was to go through issues of integrating "nature in city" but not, for instance, integrating technology into the city. Here, we can find that the designer has added new constraints to what is given to enlarge the scope of the problem. These two goals (to be iconic + not to represent UK's heritage directly) become the frame of the design problem that shows the architect's personal point of view about the project:

"...the frame deals with London's contribution in enhancing nature into the city. It is not a cultural nor a technical issue, rather it is related to nature." (source: the researcher), see Figure 3.

\section{Organising Concept}

Figure 4 shows the structure of the organizing concept.The designer extends his search into the issue of the problem frame, trying to find an interesting point to highlight. By returning to the history of planning in London he found that London was a pioneer in developing public parks in the city. Victorian parks in London were the first parks in Europe. Apparently, the designer widens the scope not horizontally but vertically in order to be more specific in identifying clearly a possible concept. He digs deep into the framing issues looking for areas of interest in this frame by answering questions of what, where, when, who. This step is essential for developing a kind of concept that is called the "organising concept."

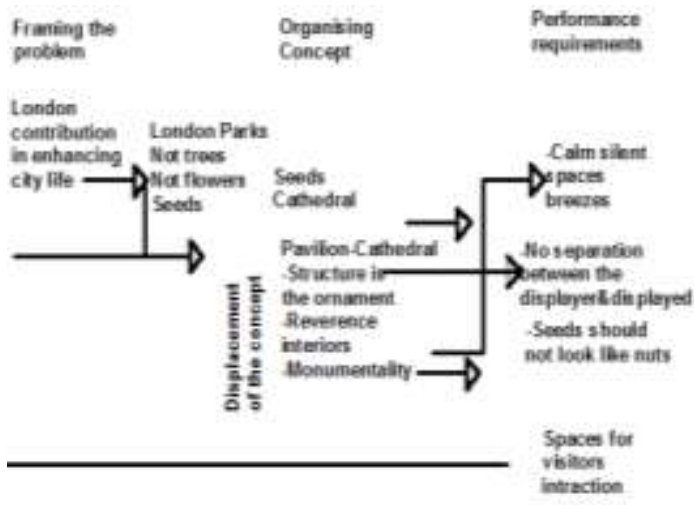

Figure 4.The structure of the organising concept

He found that "the UK was the first country to open a major botanical garden- the Royal Botanic Gardens at Kew" where a seed bank was established to collect the seeds of world wild plant species.

Here the designer found an interesting point that was hidden from us and on which he wanted to shed light; it is not the trees of the Victorian parks, nor the flowers but it is the seeds. Nobody before had thought about it: The designer wanted to represent 
the Kew seed bank, he said it is simply "a Seed Cathedral."

Representing Kew's seed bank becomes the organising concept, and a displacement of the concept has taken place when the designer used the metaphorical phrase "Seed Cathedral"; it is simply a Cathedral / Pavilion.

Apparently, the insight occurs and the abductive reasoning has taken place. Returning to the diagram, Figure 4, it shows that this concept of a Cathedral does not have any relationship or associations with any of the goals or ideas developed in the previous step.

The two cognitive operations that indicate the system mind can be found easily:

- the concept of the Seed Cathedral comes just after increasing the information by digging deep vertically into the frame. This helps the designer in being more selective when choosing what is unique and distinct.

- forging connections; there is a combination between two lines of thought: the designer combined both the thematic ideas of Nature/Park/Seeds with the idea of no separation between the displayer and the displayed. This latter has been developed as a programme goal idea. The designer solved the problem of what should be displayed and achieved the goal of making the structure as a direct manifestation of what was to be displayed.

At the bottom of Figure 4 another two lines of thought have been developed, parallel to the line of the organising concept. The first one is the concept of "the structure that can move in the wind." This line emerges from the combination of two ideas: the use of structure/ envelope language, which is part of the designer's point of view in defining architecture, and the idea of making use of waterborne breezes from the river. The second line of thought started with developing the economic goal of "making affordable use of space" by occupying only a small part of the plot with the building and leaving the rest as a landscape. This leads later to the idea of using landscape as an interactive space for visitors. In this way three strong lines of thought have been developed, see Figures 6 and 7.

\section{Performance Requirements}

Working on the organising concept has led to the identification of the performance requirements of the spaces, Figure 4. It also leads to making a displacement to the definition of "Pavilion"; shifting the pavilion beyond the common definition of what a pavilion is about. Donald Schön wrote a book about displacement of concepts, in which he established a theory for creating new concepts from old ones. He considered it as a process of shifting the old concept to a new situation: "... In this process the old concept is not applied to the new situation, as a concept to an instance, but is taken as a symbol or metaphor for the new situation." [9]. Developing a new concept using a metaphor can be achieved through making, elaboration and correction of the metaphor. Schön divided the process into four phases:

- transposition, which is the making of a metaphor. when you use a well-known term or thing to describe something else, it is considered to be the first shift for old concept.

- interpretation, which is the elaboration of the metaphor and shifting the old concept to the new situation: " ...we do not transpose an old concept to a new situation without transposing it to some specific aspect of the new situation." [9].

- correction, the new situation that has its own conceptual structure and which can resist the transposition and interpretation. These aspects of resistance have to be adjusted; some aspects of the metaphor do not suit the new situation and have to be changed.

- spilling out; making the metaphor more familiar with the new situation. Schön calls it the dying of the metaphor; being able to distinguish well between the old and the new use of the metaphor.

These four phases are the bias for the displacement of concepts, the way in which a new hypothesis emerges from an old one.

Returning to the pavilion example, the displacement is achieved by selecting certain properties and characteristics of a Cathedral and shifting the common definition of a pavilion towards them. The characteristics of a cathedral chosen for this shift are related to the symbolic meaning of the cathedral, and to be more specific, it is the thing that makes it an icon.

The pavilion is now something very large, a calm space or building almost the same as the iconic building and divine sanctuary of a cathedral. It is a large volume space with reverence and silent interiors and its structure is that of a displayer, it is almost ornamented in a way similar to the "Gothic Cathedral" where the structure is ornamented like sculpture, the structure of the pavilion is to display the seeds.

So this shift has occurred as a result of thinking into the organising concept in terms of how it could produce something iconic, a line of thought that has been established as a response to the client requirements (see Figure 6, first column of premises). That means the designer has experienced one of the operations of the system mind, namely forging connections. The designer induces the performance requirements from this new definition of the pavilion as an iconic monumental and silent construction that displays itself instead of having collections other than the seeds.

Most of the performance requirements and their developed ideas are related to the induced new definition of a pavilion: relaxing calm spaces with no separation between the displayer and the displayed... 


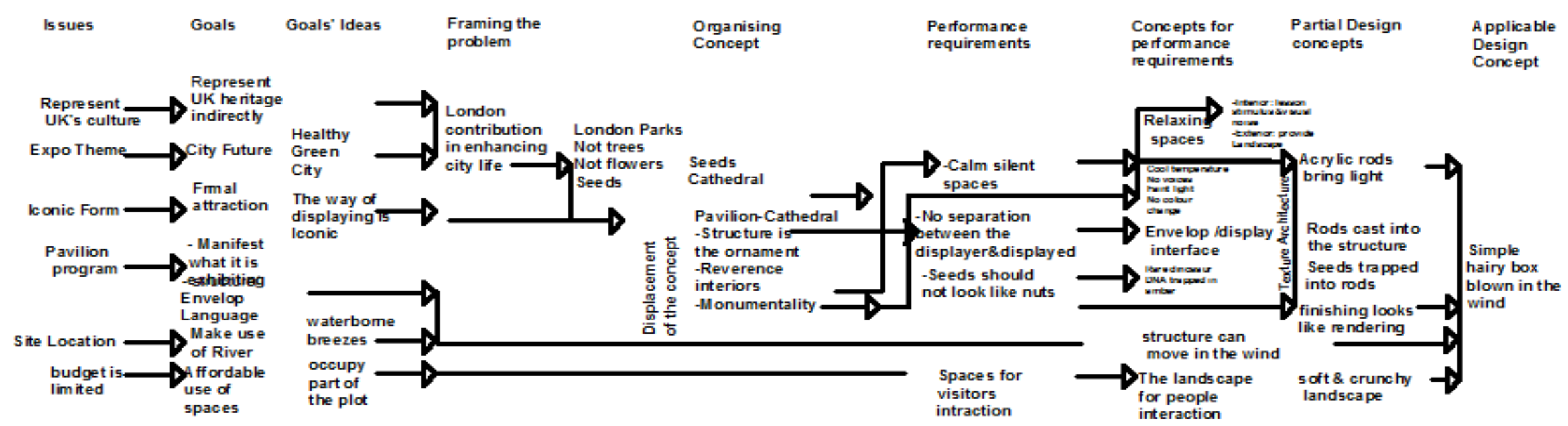

Figure 6. Structure of parallel lines of thought

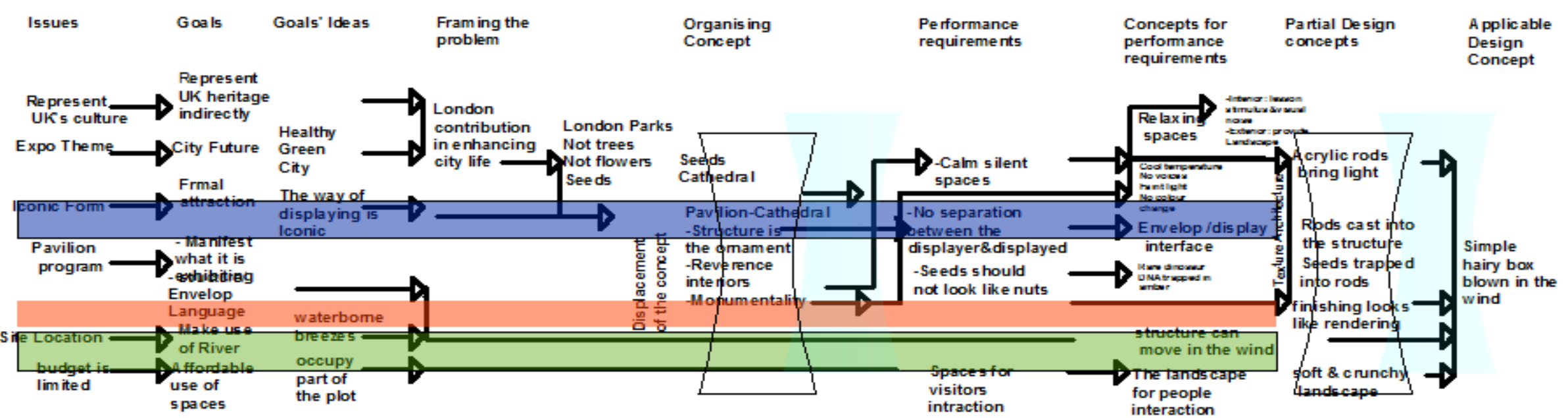

Figure 7. Three Parallel Lines of Thought 


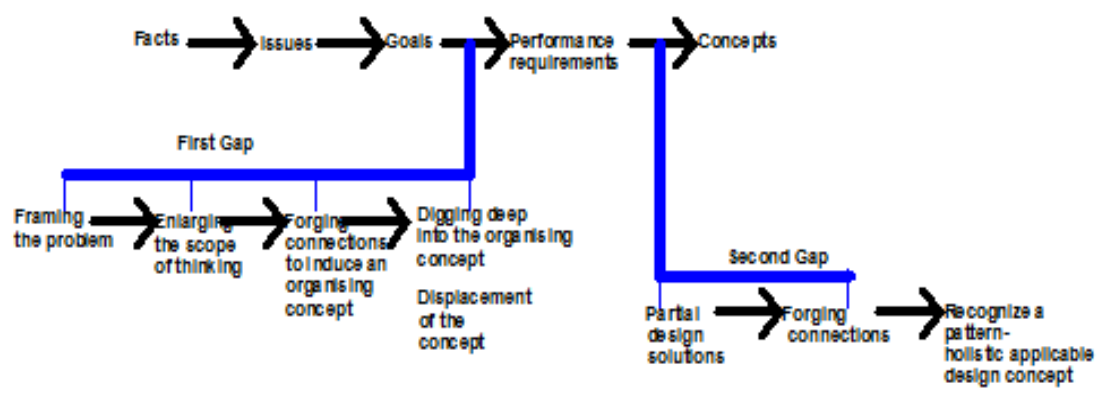

Figure 8. Developed structure of creative design thinking

The first gap comes after forming the goals, and includes the following steps: framing the problem, enlarging the scope of thinking, forging connections to induce the organising concept, and digging deep into the organising concept to make a displacement. The second gap includes these steps: provide partial design solutions, forging connections, recognise a pattern of thought/ holistic applicable design concept.

\section{Conclusions}

The two operations of widening the scope and forging connections have been used throughout the process, however, they have been used effectively in two places when designing the concept. Abductive reasoning has been used and the corresponding insight has taken place twice: $\mathrm{n}$ developing the organizing concept and also in developing the applicable design idea. The study also finds that forging connections has been used by accumulation in terms of combining additional lines of thought to the ideas in hand.

The structure of managing the design process introduced by Donna Duerk has been used successfully to show the lines of thought of the designer. While analysing the case study, the structure has been developed to reveal the hidden steps of creative thinking. Figure 8 shows the developed new structure of creative thinking used to manage the design process. It should be stated here that the linear structure does not mean that the process is linear, it is only used to clarify the steps. The first row shows Duerk's structure, the second and third rows show the developed parts. The second row illustrates the first part of hidden steps, which distinguish the creative thinking using a broad systems approach or system mind. These steps come after developing the goals and their related ideas. They include:

- framing the problem where the first shift in thinking occurs by changing the constraints of the given problem. The designer delivers a statement that shows his/her own point of view;
- widening the scope of thinking; after selecting the part of the problem which would be in focus, the designer enlarges the scope of thinking by digging deep into the problem to shed light on the hidden part which has never been seen before and highlights it;

- the organising concept is induced by enlarging the scope of thinking in the previous step and also by forging connections, which is the second cognitive operation of system mind. In this case study the organising concept comes in the form of a metaphor. It is noticed that the designer used the metaphor to develop the organising concept (Seeds Cathedral), and also in describing some partial solutions. For example, describing the way of creating the pavilion entrance as shaving, "....you know when a pet has an operation and they shave a bit of skin and get rid of the fur- in order to get you to go into the seed cathedral, in effect, we've shaved it."(TedTalk, transcript. https://www.ted.com/talks/thomas_heatherwick).

Another example is the technique used to cast the acrylic rods into the steel structure which is described as "the growing hair" of a famous toy that has been used in TV advertisements. This might be related to the designer's own interest in metaphor.

- displacement of the concept: it can be seen that the development of the organising concept has led to the displacement of the concept of the pavilion, which in turn suggested new qualities and performance requirements for the building.

The third row in figure 8 shows the second part of the hidden steps of creative thinking, these include:

- development of partial solutions /partial design concepts;

- development of a holistic applicable concept that is the physical design concept.

In revealing this second gap, the study discovers that there is a pattern of connections appearing among the partial design solutions and it could be the reason behind the emergence of a holistic applicable design concept. However, this study does not answer the question of what properties of the emergent patterns have a direct influence on the generation of 
a new applicable design concept. Kolko [5] described some of their characteristics as being multi-faceted, rooted in culture and complex, we need a further study to check these aspects.

The study also discovers that the designer works on the first principles of design in order to reach an overall image of the applicable design concept. This finding confirms what Nigel Cross has suggested as a conclusion in his study for innovative designers. He considered working on the first principles of design as one of the three key strategic aspects of creative design thinking.

Finally, it seems that designers dependheavily on their previous experience to bring life to their new designs and give them an image as a 3D structures, and this is what gives an identity to their designs. Thomas Heatherwick depended on his interest and experience in 'Texture Architecture' to create the hairy pavilion. He has experienced the hairy form in a previous small project, namely the 'Sitooterie' or the small summer house, at Barnards Farmin Essex. We have to affirm here that the whole process of creation is not linear and the suggested scenario in which all the data are presented is one possible way of many. We cannot guarantee which comes first: is it the idea of a 'hairy form' or the idea of "Seed Cathedral", on which the whole story was developed.

\section{References}

[1] Cross, Nigel, Design thinking, understanding how designers think and work, Bloomsbury Academic an imprint of Bloomsbury publishing Plc., London, UK, 2011.

[2] Dark, J., "The primary generator and the design process", Design Studies Issue 1 Vol.1, ELSEVIER, Netherlands, July 1979, 36-44.

[3] Duerk, D. P., Architectural programming, Information management for design, John Willey \& Sons, Inc., Canada, 1993.

[4] Hudson, J., Architecture from commission to construction, Laurence king publishing Ltd., London, 2012.

[5] Kolko, J., "Abductive Thinking and sense making: The drivers of design synthesis", Design Issues: November 1 Winter volume 26, MIT, USA, 2010.

[6] Lawson, Bryan, 'Parallel lines of thought', Research Gate; https://www.researchgate.net/publication/257353502 _Parallel_lines_of_thought. (January, 1993).

[7] Pourdehnad, J., Wexler, Erica R. \& Wilson, Dennis, " Systems \& Design Thinking: a conceptual framework for their integration", A paper presented at the International Society for the Systems Sciences (ISSS). 55th Annual Conference, "All Together Now: Working Across Disciplines," at University of Hull, Hull, UK, July 17-22, 2011. Reprinted by permission.
[8] Rowe, P.G, Design Thinking. The MIT Press, Cambridge Mass, 1987.

[9] Schön, Donald, Displacement of Concepts, First published by Tavistock Publications Limited 1963, Routledge, New York, 2011.

[10] Yatt, Barry D., 'Critical Thinking for Architects: Developing a Project Premise and Concept', SCRIBD Research; https://www.scribd.com/document/326837243/ Critical-Thinking-for-Architects. AIA, CSI 2000. 